\title{
Influence of host habitat on the occurrence of gill monogeneans Pseudodactylogyrus spp. on wild Japanese eels Anguilla japonica
}

\author{
Hirotaka Katahira ${ }^{1, *}$, Kouki Mizuno ${ }^{1,2}$, Tetsuya Umino ${ }^{1}$, Kazuya Nagasawa ${ }^{1}$ \\ ${ }^{1}$ Graduate School of Biosphere Science, Hiroshima University, 1-4-4 Kagamiyama, Higashi-Hiroshima, Hiroshima, \\ 739-8528 Japan \\ ${ }^{2}$ Ehime Prefectural Uwajima Fishery High School, 1-2-20 Meirin, Uwajima, Ehime, 798-0068 Japan
}

\begin{abstract}
With technological improvements in otolith microchemical analysis, the flexible use of habitat from coastal marine to fresh waters has been discovered in Japanese eels Anguilla japonica. We examined the occurrence of 3 congeneric gill monogeneans - Pseudodactylogyrus anguillae, $P$. bini, and $P$. kamegaii- on wild Japanese eels, in relation to the host's flexibility. From April 2008 to October 2009, 114 eels were collected from a brackish-water cove and 2 rivers flowing into the cove in Ehime Prefecture, western Japan. Based on otolith microchemical analysis, the eels were discriminated according to the following 4 types of habitat use: freshwater residents (Type I), individuals utilizing low-salinity habitats (Type II), downstream habitat-shifters (Type III), and cove residents (Type IV). P. anguillae occurred mainly on Type I and II eels, while $P$. bini was primarily found on Type I eels. In contrast, $P$. kamegaii occurred mainly on Type III and IV eels. Thus, we conclude that species composition and infection levels of Pseudodactylogyrus spp. clearly differed with habitat-use patterns of Japanese eels. Also, since P. anguillae was scarcely found on either Type III or IV eels, this study suggests that previous identifications of monogeneans collected from European brackish-water localities as $P$. anguillae may require verification.
\end{abstract}

KEY WORDS: Parasites · Monogenea P Pseudodactylogyrus · Japanese eels · Anguilla japonica · Otolith $\cdot$ Sr:Ca ratio

\section{INTRODUCTION}

Anguillid eels have a unique life history, characterized by migration to distant, oceanic spawning grounds after spending a significant part of their lifetime in freshwater habitats (McDowall 1988). This dynamic migratory loop is termed 'catadromy' (McDowall 1988), and eels have long attracted a great deal of biological interest as representatives of economically important catadromous fish species (reviewed by Tesch 2003). Recently, a microchemical analysis, based on the ratio of strontium (Sr) to cal- cium $(\mathrm{Ca})$ in the otoliths of both European (Anguilla anguilla [Linnaeus, 1758]) and Japanese eels (Anguilla japonica Temminck \& Schlegel, 1846), indicated that some individuals within a population are found in fresh waters, while others reside primarily in highsalinity habitats during their growth phase, without migrating into freshwater environments (Tsukamoto et al. 1998). In addition, various patterns of habitat usage, such as brackish-water residency (e.g. Tsukamoto \& Arai 2001) and several types of habitat shifting (e.g. Kaifu et al. 2010), have been reported for European and Japanese eels, as well as further 
anguillid species (see Chino \& Arai 2010), by using the same microchemical technique.

Thus, eels should currently be considered a facultative catadromous fish with various habitat-use patterns called ecophenotypes (Tsukamoto et al. 2002). However, these ecophenotypes of eels have largely been ignored in parasitological investigations. As far as we know, there has only been a single study to date, by Han et al. (2009), dealing with the relationship between facultative catadromy and parasite infection. Based on otolith microchemical analysis, they detected the infection of a freshwater nematode, Anguillicoloides crassus (Kuwahara, Niimi \& Itagaki, 1974) Moravec \& Taraschewski, 1988 (Anguillicolidae), in multiple habitat-shifters that move between marine-coastal and freshwater habitats, within a population of Japanese eels in Taiwan, and concluded that facultative catadromy potentially contributes to the dispersion of this pathogenic nematode. This flexible behavior appears to be closely involved in parasite ecology from individual to community levels. Even if a parasite is well studied under natural conditions, it may need to be reinvestigated with regard to its host's flexibility.

Pseudodactylogyrus anguillae (Yin \& Sproston, 1948) Gusev, 1965; P. bini (Kikuchi, 1929) Gusev, 1965; and P. kamegaii Iwashita, Hirata \& Ogawa, 2002 (Ancyrocephalidae: Pseudodactylogyrinae) are monogenean gill parasites of Japanese eels (Ogawa \& Egusa 1976, Iwashita et al. 2002). Both P. anguillae and P. bini are commonly found on Japanese eels (Ogawa \& Egusa 1976, Nagasawa et al. 2007), with a history of spreading to European eels via commercial transportation of live Japanese eels from Asia to Europe (Buchmann et al. 1987b, Hayward et al. 2001, Kania et al. 2010). These monogeneans feed exclusively on the mucus and epithelial tissues of the gill surface (Buchmann et al. 1987a), but their hamuli can inflict damage to and deformation of host tissues (Chan \& Wu 1984, Buchmann et al. 1987a,b). Economic losses to eel farms have sometimes been reported, due to stress induced by heavy infections with these parasites (reviewed by Køie 1991, Kennedy 2007). Since European eels are especially prone to being heavily infected and impaired by both monogeneans (Ogawa \& Egusa 1976, Egusa 1979, Fang et al. 2008), the current state of invasion is under scrutiny in European countries, where $P$. anguillae has been reported from freshwater to brackish-water environments, while $P$. bini has been found only in freshwater (reviewed by Jakob et al. 2009). In contrast, investigations of the 2 monogeneans in wild Japanese eels are quite few (see Naga- sawa et al. 2007), because they rarely cause a problem. Thus, the host-parasite relationships in Japanese eel populations have never been completely clear. The one remaining species, P. kamegaii, was described by Iwashita et al. (2002) as a valid species from Japanese eels caught at the mouth of a river flowing into Tokyo Bay in Japan, but there has been no subsequent record for this species.

The aim of the present study was to examine the infection status of Pseudodactylogyrus spp. on wild Japanese eels, considering distinctions in the host's facultative catadromy. For this purpose, we combined a traditional parasitological survey with otolith microchemical analysis on the eels inhabiting a brackish-water cove and 2 rivers flowing into the cove in western Japan.

\section{MATERIALS AND METHODS}

\section{Sample collection}

The sampling was conducted in Misho Cove (salinity range: 3.6 to $30.7 \%$ ) and 2 adjacent rivers, the Renjoji and Sozu Rivers, flowing into the cove in Ehime Prefecture, western Japan (Fig. 1). In these localities, Japanese eels Anguilla japonica were caught with covert traps and eel pots from April 2008 to October 2009. The eels collected were kept alive in oxygenated containers with ambient waters and brought to the laboratory at Hiroshima University, where they were measured for total length (TL, in $\mathrm{mm}$ ) and examined for parasites within a few days.

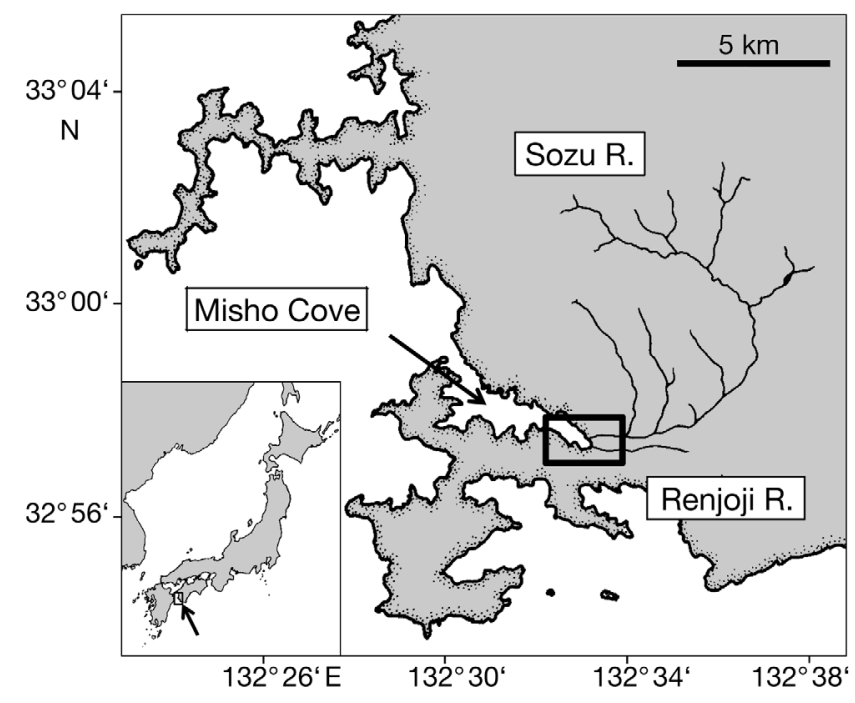

Fig. 1. Map of the study area. Japanese eels Anguilla japonica were collected in the boxed area 
All pseudodactylogyrid monogeneans recovered from the gills of eels were fixed in $70 \%$ ethanol under slight pressure. These specimens were subsequently stained with Heidenhain's iron hematoxylin or Alum carmine, dehydrated in a series of ascending concentrations of ethanol, cleared in xylene, and mounted in Canada balsam. Identifications of Pseudodactylogyrus spp. were confirmed according to the descriptions by Ogawa \& Egusa (1976) and Iwashita et al. (2002): P. bini apparently has smaller hamuli than both $P$. anguillae and $P$. kamegaii and $P$. kamegaii differs from $P$. anguillae in having a wider and sclerotized cirrus and vagina and shorter marginal hooks. Specimens of Pseudodactylogyrus spp., including the holotype and paratypes of $P$. kamegaii, deposited in the collections of the Meguro Parasitological Museum (MPM), Tokyo, were also used to confirm our identifications: $P$. anguillae (MPM Coll. Nos. 19139, 19140a, 19140c, 19164a, 19165a, 19166a, 19166c, 19168c, 19169a, 19171c), P. bini (MPM Coll. Nos. 19140b, 19141, 19165c, 19166d, 19167a, 19168a, 19170a, 19171b), and P. kamegaii (MPM Coll. Nos. 19767-19768).

\section{Otolith preparation and $\mathrm{Sr}: \mathrm{Ca}$ ratio analysis}

Sagittal otoliths were extracted from each Japanese eel when the parasitological examination was carried out. All otoliths were first stored in $70 \%$ ethanol and embedded in epoxy resin after air-drying. Subsequently, they were ground using a grinding machine (Struers S5629, Marumoto Struers K.K.) to expose the core along a horizontal plane. For the finishing polish, $1 \mu \mathrm{m}$ diameter diamond paste with lubricant liquid was used. Each otolith polished was then coated with carbon in a high-vacuum evaporator, and $\mathrm{Sr}$ and $\mathrm{Ca}$ concentrations were measured along the line from core to edge at intervals of $10 \mu \mathrm{m}$ using an electron probe microanalyzer (JOEL JXA8200 ; the accelerating voltage and beam current were $15 \mathrm{kV}$ and $10 \mathrm{nA}$, respectively). $\mathrm{SrCO}_{3}$ and $\mathrm{CaCO}_{3}$ were used as standards. The electron beam was focused on a point $10 \mu \mathrm{m}$ in diameter, with $10 \mathrm{~s}$ of irradiation per point.

The Sr:Ca measurement values were used to interpret the habitat usage of Japanese eels, based on the criteria of Tsukamoto \& Arai (2001): Sr:Ca ratios $<2.5$ $\times 10^{-3}$ correspond to freshwater living, Sr:Ca ratios ranging from $2.5 \times 10^{-3}$ to $6.0 \times 10^{-3}$ indicate brackish-water living, and Sr:Ca ratios $>6.0 \times 10^{-3}$ indicate eels living in a high-salinity environment such as seawater.

\section{Data analysis}

Prevalence (percentage of host individuals infected with a parasite), mean intensity (the average number of individuals of a parasite per infected host), and mean abundance (the average number of individuals of a parasite per examined host) of monogeneans were calculated for each ecophenotype of host, in accordance with the definitions of Bush et al. (1997).

Generalized linear models (GLM) were applied to examine relationships between the abundances and biological parameters of eels using R 2.8.1 (R Development Core Team 2008) with the MASSpackage (Venables \& Ripley 2002). In this analysis, ecophenotype and TL of eels were tested as explanatory variables. For the fitting of models to the abundances of Pseudodactylogyrus spp., a negative binomial error distribution and a logarithmic link function were employed, because macroparasites often represent aggregated infection patterns, which are best described as a negative binomial distribution, in their host population (Wilson et al. 1996, Shaw et al. 1998). The candidate models were selected by a forward stepwise procedure based on Akaike's information criterion (AIC; Burnham \& Anderson 2002). The difference in $\mathrm{AIC}$ value $(\triangle \mathrm{AIC})$ between a constructed model and a model with the lowest AIC value was also calculated: as a rule of thumb, a model with $\triangle$ AIC $<2$ is substantially supported and received consideration in making data inference (see Burnham \& Anderson 2002).

\section{RESULTS}

\section{Habitat-use patterns of Japanese eels}

A total of 114 Japanese eels Anguilla japonica were collected from 3 localities during the sampling period. The eels ranged from 204 to $684 \mathrm{~mm}$ TL, with a mean $( \pm \mathrm{SD})$ of $382 \pm 74.5 \mathrm{~mm}$ TL. Based on their otolith Sr:Ca ratios, the eels were divided into 4 categories of ecophenotype (i.e. habitat-use patterns) (Fig. 2): freshwater residents (designated hereafter as Type $\mathrm{I}, \mathrm{n}=22$ ), individuals moving between freshwater and low-salinity habitats (Type II, $\mathrm{n}=19$ ), downstream habitat-shifters which reside in the cove after migrating down from freshwater habitats (Type III, $\mathrm{n}=51$ ), and cove residents without any migration into freshwater (Type IV, $\mathrm{n}=22$ ). 


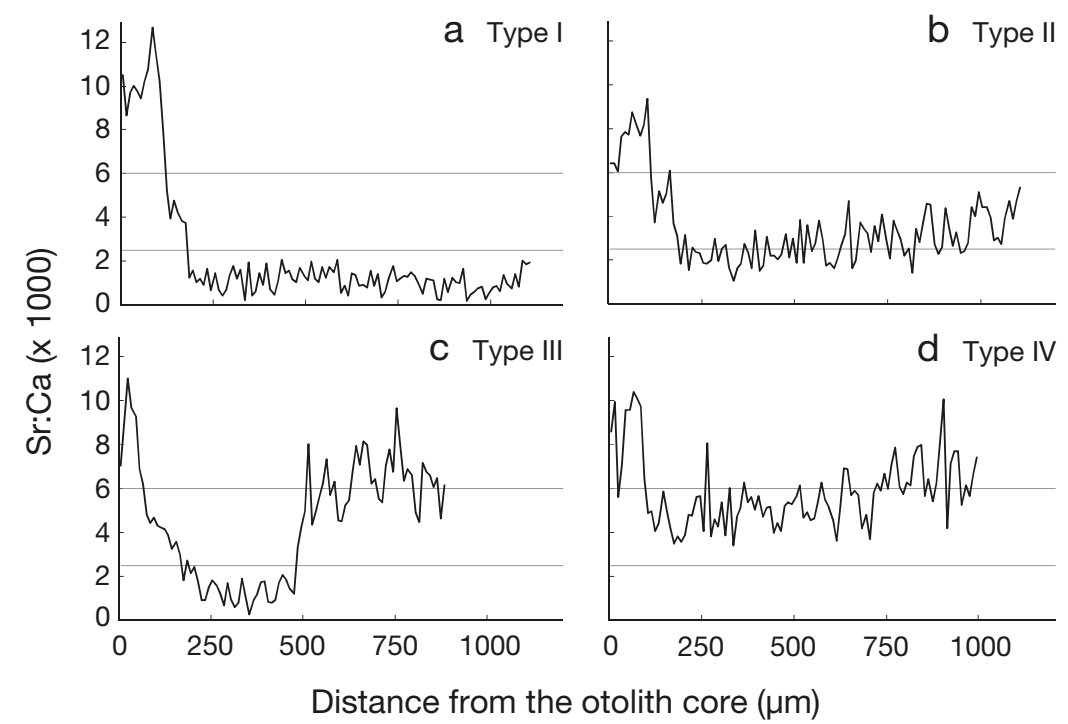

Fig. 2. Anguilla japonica. Typical changes in otolith Sr:Ca ratios along a transect line from the core $(0 \mu \mathrm{m})$ to the edge of the otolith in Japanese eels, collected from Misho Cove and the Renjoji and Sozu Rivers. (a) Type I: freshwater resident, (b) Type II: individual utilizing low-salinity habitats, (c) Type III: downstream habitat-shifter, and (d) Type IV: cove resident. Horizontal lines indicate $\mathrm{Sr}$ : Ca ratios of $2.5 \times 10^{-3}$ and $6.0 \times 10^{-3}$

\section{Parasite occurrence}

All 4 ecophenotypes of Japanese eels were infected with at least 1 species of Pseudodactylogyrus (Table 1). Type I eels were infected by $P$. anguillae and $P$. bini. Type II eels harbored 3 species of Pseudodactylogyrus. Type III eels were infected with $P$. anguillae and $P$. kamegaii. In Type IV, only $P$. kamegaii occurred.

As a result of the model selections, the abundances of Pseudodactylogyrus bini and P. kamegaii were confirmed to significantly vary with host ecophenotypes and TL (Table 2). For P. anguillae abundance, the multivariate model composed of 2 explanatory variables (ecophenotype and TL) represented no improvement over the AIC value from the univariate model consisting of ecophenotype. However, due to the slight difference in AIC value $(\triangle \mathrm{AIC}=0.44)$ from the univariate model, the multivariate model could not be eliminated. In the present study, thus, the multivariate model was tentatively accepted as the final model for $P$. anguillae abundance, according to the models for $P$. bini and $P$. kamegaii abundances.

In all final models, Pseudodactylogyrus spp. abundances were positively, yet only slightly, associated with host TL (Table 3). The abundances of $P$. anguillae and $P$. bini also increased with the ranking of the 4 types of eel habitats from saline to freshwater. In contrast, $P$. kamegaii severely infected the 2 host groups (Type III and IV) inhabiting brackish-water areas.

\section{DISCUSSION}

Anguillid eels are thought to be derived from a marine ancestor that completed its migration loop within the ocean (Tsukamoto et al. 2002, Inoue et al. 2010). The genus Pseudodactylogyrus is also assumed to be of marine origin (Ogawa 1984), and Iwashita et al. (2002) speculated that the freshwater congeners $P$. anguillae and $P$. bini diverged from their marine ancestor as their host went through evolutional adaptation from marine to freshwater environments, whereas $P$. kamegaii originates from the ancestor remaining in coastal marine and brackish-water environments. No occurrence of $P$. kamegaii was found in freshwater residents, designated as Type I in the present study, thus indicating that this monogenean has maintained the original marine distribution by parasitizing non-catadromous eel individuals since divergence. If all eel individuals had a catadromous life-history, migrating up to freshwater habitats, $P$. kamegaii might not have survived or might have been forced to adapt to freshwater habitats.

Table 1. Anguilla japonica. Infection levels of Pseudodactylogyrus spp. on Japanese eels from Ehime Prefecture, western Japan, with distinction of 4 habitat-use patterns in eels. N: sample size; TL: mean total length $( \pm \mathrm{SD})$; P: prevalence; MI: mean intensity $( \pm \mathrm{SD})$; MA: mean abundance $( \pm S D)$; for type descriptions, see Fig. 2

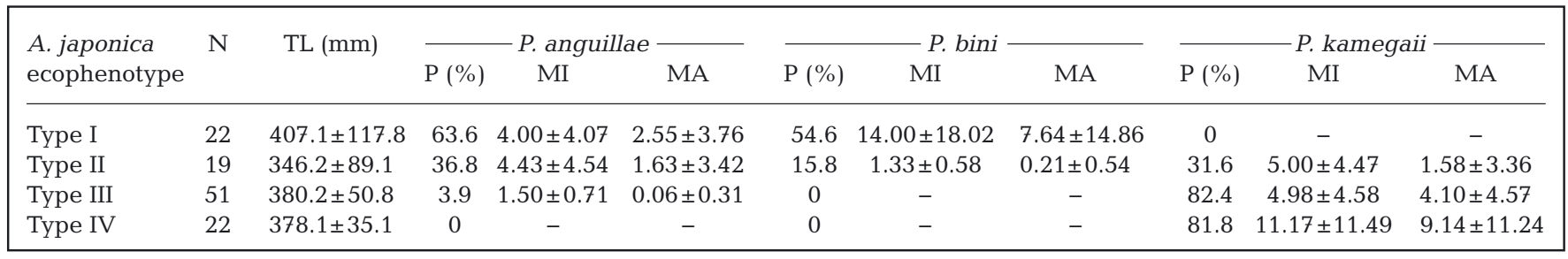


Table 2. Forward stepwise generalized linear model constructions for explanatory variables affecting Pseudodactylogyrus spp. abundances on Japanese eels Anguilla japonica. AIC: Akaike's information criterion; null: a model with no explanatory variable; TL: total length

\begin{tabular}{|lcccc|}
\hline Model & $\begin{array}{c}\text { Residual } \\
\text { df }\end{array}$ & $\begin{array}{c}\text { Residual } \\
\text { deviance }\end{array}$ & AIC & AAIC \\
\hline P. anguillae & & & & \\
Null & 91 & 51.48 & 206.70 & 26.22 \\
+ Ecophenotype & 89 & 50.45 & 180.47 & 0 \\
+ Ecophenotype + TL & 88 & 50.91 & 180.92 & 0.44 \\
P. bini & & & & \\
Null & 40 & 29.42 & 153.71 & 14.81 \\
+ Ecophenotype & 39 & 29.71 & 142.65 & 3.76 \\
+ Ecophenotype + TL & 38 & 31.95 & 138.90 & 0 \\
P. kamegaii & & & & \\
Null & 91 & 100.6 & 481.13 & 13.47 \\
+ Ecophenotype & 89 & 100.8 & 469.94 & 2.29 \\
+ Ecophenotype + TL & 88 & 100.1 & 467.66 & 0 \\
\hline
\end{tabular}

Table 3. Estimated effects of explanatory variables selected in the final models. TL: total length; for type descriptions, see Fig. 2

\begin{tabular}{|lccccc|}
\hline Parameter & & Estimate & SE & z-value & $\mathrm{p}$ \\
\hline $\boldsymbol{P}$. anguillae & & & & & \\
Intercept & & -0.777 & 0.998 & -0.778 & 0.437 \\
Ecophenotype & Type I & 0.218 & 0.581 & 0.376 & 0.707 \\
& Type II & 0 & & & \\
& Type III & -3.392 & 0.752 & -4.510 & $<0.001$ \\
TL & & 0.003 & 0.003 & 1.351 & 0.177 \\
$\boldsymbol{P}$ bini & & & & & \\
Intercept & & -4.571 & 1.283 & -3.564 & $<0.001$ \\
Ecophenotype & Type I & 2.537 & 0.737 & 3.442 & $<0.001$ \\
TL & Type II & 0 & & & \\
$\boldsymbol{P}$ kamegaii & & 0.009 & 0.003 & 2.944 & 0.003 \\
Intercept & & & & & \\
Ecophenotype & Type II & 0 & & & \\
& Type III & 1.001 & 0.391 & 2.560 & 0.011 \\
TL & Type IV & 1.723 & 0.435 & 3.961 & $<0.001$ \\
& & 0.005 & 0.002 & 2.212 & 0.027 \\
\hline
\end{tabular}

Conversely, the presence of $P$. kamegaii probably indicates the resource stability of non-catadromous individuals that primarily inhabit coastal and brackish-water areas.

In European countries, Pseudodactylogyrus anguillae or unidentified species of Pseudodactylogyrus have sometimes been reported from European eels in brackish-water localities, with relatively high prevalence and intensity: for example, 2 fjords (salinity: 15 to $20 \%$ and about $10 \%$, respectively) adjoining the Baltic and North Seas and a strait (4 to $8 \%$ ) within the Baltic Sea, Denmark (Køie 1988); a lagoon (10 to
$40 \%$ ) in the North Tyrrhenian Sea (Kennedy et al. 1997 ) and 2 lagoons (15 to $35 \%$ and 30 to $42 \%$, respectively) in the North Adriatic Sea, Italy (Di Cave et al. 2001); 3 lagoons (3 to $30 \%$, 8 to $36 \%$, and 8 to $30 \%$, respectively) in the Balearic Sea, Spain (Maillo et al. 2005); lagoons (no salinity data) in the Gulf of Lion, Mediterranean Sea, France (Fazio et al. 2008); and a lagoon, a fjord, and a strait (overall salinity range: 15 to $26 \%$ ) in northwestern Germany (Jakob et al. 2008). However, it is noteworthy that $P$. anguillae was scarce on the Japanese eels inhabiting Misho Cove ( 3.6 to $30.7 \%$ ) in the present study, with a low intensity if present at all. Instead, these cove eels were exclusively infected with $P$. kamegaii, even if the eels were identified as Type III, i.e. having migrated down from the freshwater habitats where $P$. anguillae is mainly distributed. Therefore, our findings in the present study suggest that some of the monogenean specimens from brackish-water localities in Europe previously reported to be $P$. anguillae may actually have been $P$. kamegaii.

Pseudodactylogyrus kamegaii and P. anguillae are easily confused because their morphologies are very similar (see Iwashita et al. 2002), but P. kamegaii can be distinguished from $P$. anguillae by its wider and sclerotized cirrus and vagina and shorter marginal hooks (Iwashita et al. 2002. To date, no information on occurence of P. kamegaii is available, except for that provided in the present study and that from the first record by Iwashita et al. (2002) based on specimens from Japanese eels. Unfortunately, there are no reports on the current status of $P$. kamegaii in European countries. However, in view of recent reports that European eels are also facultatively catadromous (Tsukamoto et al. 1998, Arai et al. 2006, Daverat et al. 2006), P. kamegaii appears to be able to survive and sustain its population by utilizing coastal marine and brackish-water residents of European eels, just like the present case in Japanese eels. Further investigations are therefore needed in European countries, not only of $P$. anguillae and $P$. bini, but also of $P$. kamegaii, to examine its existence there.

If Pseudodactylogyrus kamegaii does not exist in Europe, the discrepancy in the occurrence of $P$. anguillae between the current findings in European countries and our data in Japan suggest another explanation. According to Køie (1991), P. anguillae is capable of reproducing in brackish-water salinities up to $20 \%$. Even though this species can occur in relatively high-salinity environments, its distribution is possibly restricted to freshwater environments because it rarely co-occured with $P$. kamegaii: only 3 cases of coexistence on the same eel individual were 
observed in the present study (Table 1). On the other hand, as reported in European countries (Buchmann 1988, Dzika 1999, Fang et al. 2008), the coexistence of $P$. anguillae and $P$. bini was confirmed in our study. In either case, salinity tolerance of each monogenean species needs to be reinvestigated under experimental conditions, especially with regard to a possible revision of the range of $P$. anguillae.

The present study also detected slight positive relationships between the host's body size and the infection level of each species of Pseudodactylogyrus. A similar positive relationship has also been documented for cultured and wild European eels (Buchmann 1989, Nie \& Kennedy 1991, but see Køie 1988), and it is presumed that higher infection levels in larger eels are attributable to a higher probability of infection of the gill due to more space for parasite attachment and greater flows of water (Buchmann 1989, Nie \& Kennedy 1991). The size-related principle, as previously suggested, may work for all 3 Pseudodactylogyrus spp.

In conclusion, the present study showed among that species composition and infection levels of Pseudodactylogyrus spp. clearly differ among the habitatuse patterns of Japanese eels. The concomitant use of microchemical analysis can reveal the relationship between the host's ecophenotypes and the infection status of the gill monogeneans, and eventually afford a useful baseline to determine the distributional ranges of the monogeneans from coastal marine to freshwater environments. This technique could also help to investigate other eel parasites. Further applications could, therefore, enable a greater understanding of the patterns and processes of parasite assemblages in the facultative catadromy of eels. Other fish species undertaking regular, seasonal, or ontogenetic migration between marine and freshwater environments also represent flexible migratory diversity (see Yang et al. 2011), as well as the cases of anguillid eels. In cases where these fishes are examined for parasites, otolith microchemical data are needed to corroborate the host's mobility.

Acknowledgements. We are grateful to the local fisherman S. Takamori and his family for assistance in the field. We acknowledge K. Ogawa, the director of Meguro Parasitological Museum (MPM), Tokyo, for the use of facilities and his advice on the identification of the present parasites. T. Iwaki, MPM, also supported the observation of voucher specimens. We thank Y. Shibata, Faculty of Science, Hiroshima University, for measuring the microchemical concentrations in otoliths. M. Iwashita, Japan Fisheries Resource Conservation Association, Tokyo, helped us collect the relevant literature. Part of this study was financially supported by a Grant-in-Aid for JSPS Fellows (No. 228025) to H.K.

\section{LITERATURE CITED}

Arai T, Kotake A, McCarthy TK (2006) Habitat use by the European eel Anguilla anguilla in Irish waters. Estuar Coast Shelf Sci 67:569-578

Buchmann K (1988) Spatial distribution of Pseudodactylogyrus anguillae and $P$. bini (Monogenea) on the gills of the European eel, Anguilla anguilla. J Fish Biol 32: 801-802

> Buchmann K (1989) Relationship between host size of Anguilla anguilla and the infection level of the monogeneans Pseudodactylogyrus spp. J Fish Biol 35:599-601

Buchmann K, Køie M, Prentø P (1987a) The nutrition of the gill parasitic monogenean Pseudodactylogyrus anguillae. Parasitol Res 73:532-537

Buchmann K, Mellergaard S, Køie M (1987b) Pseudodactylogyrus infection in eel: a review. Dis Aquat Org 3: 51-57

Burnham KP, Anderson DR (2002) Model selection and multimodel inference: a practical information-theoretic approach, 2nd edn. Springer, New York, NY

Bush AO, Lafferty KD, Lotz JM, Shostak AW (1997) Parasitology meets ecology on its own terms: Margolis et al. revisited. J Parasitol 83:575-583

Chan B, Wu B (1984) Studies on the pathogenicity, biology and treatment of Pseudodactylogyrus for the eels in fishfarms. Acta Zool Sin 30:173-180

> Chino N, Arai T (2010) Habitat use and habitat transitions in the tropical eel, Anguilla bicolor bicolor. Environ Biol Fishes 89:571-578

> Daverat F, Limburg KE, Thibault I, Shiao JC and others (2006) Phenotypic plasticity of habitat use by three temperate eel species, Anguilla anguilla, A. japonica and A. rostrata. Mar Ecol Prog Ser 308:231-241

Di Cave D, Berrili F, De Liberato C, Orecchia P, Kennedy CR (2001) Helminth communities in eels Anguilla anguilla from Adriatic coastal lagoons in Italy. J Helminthol 75: $7-13$

Dzika E (1999) Microhabitats of Pseudodactylogyrus anguillae and P. bini (Monogenea: Dactylogyridae) on the gills of large-size European eel Anguilla anguilla from Lake Gaj, Poland. Folia Parasitol (Praha) 46:33-36

Egusa S (1979) Notes on the culture of the European eel (Anguilla anguilla L.) in Japanese eel-farming ponds. Rapp P-V Reùn Cons Int Explor Mer 174:51-58

> Fang JP, Shirakashi S, Ogawa K (2008) Comparative susceptibility of Japanese and European eels to infections with Pseudodactylogyrus spp. (Monogenea). Fish Pathol 43: 144-151

Fazio G, Sasal P, Lecomte-Finiger R, Da Silva C, Fumet B, Mone H (2008) Macroparasite communities in European eels, Anguilla anguilla, from French Mediterranean lagoons, with special reference to the invasive species Anguillicola crassus and Pseudodactylogyrus spp. Knowl Manag Aquatic Ecosyst 6:390-391

> Han YS, Chang YT, Tzeng WN (2009) Variable habitat use by Japanese eel affects dissemination of swimbladder parasite Anguillicola crassus. Aquat Biol 5:143-147

Hayward CJ, Iwashita M, Crane JS, Ogawa K (2001) First report of the invasive eel pest Pseudodactylogyrus bini in North America and in wild American eels. Dis Aquat Org 44:53-60

> Inoue JG, Miya M, Miller MJ, Sado T and others (2010) Deep-ocean origin of the freshwater eels. Biol Lett 6: 363-366 
Iwashita M, Hirata J, Ogawa K (2002) Pseudodactylogyrus kamegaii sp. n. (Monogenea: Pseudodactylogyridae) from wild Japanese eel, Anguilla japonica. Parasitol Int 51:337-342

> Jakob E, Hanel R, Klimpel S, Zumholz K (2008) Salinity dependence of parasite infestation in the European eel Anguilla anguilla in northern Germany. ICES J Mar Sci 66:358-366

Jakob E, Walter T, Hanel R (2009) A checklist of the protozoan and metazoan parasites of European eel (Anguilla anguilla): checklist of Anguilla anguilla parasites. J Appl Ichthyology 25:1-49

Kaifu K, Tamura M, Aoyama J, Tsukamoto K (2010) Dispersal of yellow phase Japanese eels Anguilla japonica after recruitment in the Kojima Bay-Asahi River system, Japan. Environ Biol Fishes 88:273-282

Kania PW, Taraschewski H, Han YS, Cone DK, Buchmann K (2010) Divergence between Asian, European and Canadian populations of the monogenean Pseudodactylogyrus bini indicated by ribosomal DNA patterns. J Helminthol 84:404-409

Kennedy CR (2007) The pathogenic helminth parasites of eels. J Fish Dis 30:319-334

Kennedy CR, Di Cave D, Beriilli F, Orecchia P (1997) Composition and structure of helminth communities in eels Anguilla anguilla from Italian coastal lagoons. J Helminthol 71:35-40

Køie M (1988) Parasites in European eel Anguilla anguilla (L.) from Danish freshwater, brackish and marine locations. Ophelia 29:93-118

Køie M (1991) Swimbladder nematodes (Anguillicola spp.) and gill monogeneans (Pseudodactylogyrus spp.) parasitic on European eel (Anguilla anguilla). J Cons Int Explor Mer 47:391-398

Maillo PA, Vich MA, Salvadó H, Marqués A, Gracia MP (2005) Parasites of Anguilla anguilla (L.) from three coastal lagoons of the River Ebro delta (western Mediterranean). Acta Parasitol 50:156-160

McDowall RM (1988) Diadromy in fishes. Croom-Helm, London

Editorial responsibility: Bernd Sures, Essen, Germany
Nagasawa K, Umino T, Mizuno T (2007) A checklist of the parasites of eels (Anguilla spp.) (Anguilliformes: Anguillidae) in Japan (1915-2007). J Grad Sch Biosph Sci Hiroshima Univ 46:91-122

Nie P, Kennedy CR (1991) Occurrence and seasonal dynamics of Pseudodactylogyrus anguillae (Yin \& Sproston) (Monogenea) in eel, Anguilla anguilla (L.), in England. J Fish Biol 39:897-900

Ogawa K (1984) Pseudodactylogyrus haze sp. nov., a gill monogenean from the Japanese goby, Acanthogobius flavimanus. Kisechugaku Zasshi 33:403-405

> Ogawa K, Egusa S (1976) Studies on eel Pseudodactylogyrus. I. Morphology and classification of three eel dactylogyrids with a proposal of a new species, Pseudodactylogyrus microrchis. Bull Jpn Soc Sci Fish 42: 395-404

R Development Core Team (2008) R: a language and environment for statistical computing. R Foundation for Statistical Computing, Vienna

Shaw DJ, Grenfell BT, Dobson AP (1998) Patterns of macroparasite aggregation in wildlife host population. Parasitology 117:597-610

Tesch FW (2003) The eel. Blackwell Scientific, Oxford

Tsukamoto K, Arai T (2001) Facultative catadromy of the eel Anguilla japonica between freshwater and seawater habitats. Mar Ecol Prog Ser 220:265-276

> Tsukamoto K, Nakai I, Tesch WV (1998) Do all freshwater eels migrate? Nature 396:635-636

Tsukamoto K, Aoyama J, Miller MJ (2002) Migration, speciation, and the evolution of diadromy in anguillid eels. Can J Fish Aquat Sci 59:1989-1998

Venables WN, Ripley BD (2002) Modern applied statistics with S, 4th edn. Springer, New York, NY

Wilson K, Grenfell BT, Shaw DJ (1996) Analysis of aggregated parasite distributions: a comparison of methods. Funct Ecol 10:592-601

> Yang J, Jiang T, Liu H (2011) Are there habitat salinity markers of the Sr:Ca ratio in the otolith of wild diadromous fishes? A literature survey. Ichthyol Res 58: 291-294

Submitted: January 26, 2012; Accepted: May 3, 2012 Proofs received from author(s): July 23, 2012 